\title{
Development of fluorinated benzils and bisbenzils as room-temperature phosphorescent molecules
}

\author{
Shigeyuki Yamada"1, Takuya Higashida1, Yizhou Wang ${ }^{1}$, Masato Morita1, \\ Takuya Hosokai ${ }^{2}$, Kaveendra Maduwantha ${ }^{2,3}$, Kaveenga Rasika Koswattage ${ }^{2,3}$ \\ and Tsutomu Konno ${ }^{1}$
}

\section{Full Research Paper}

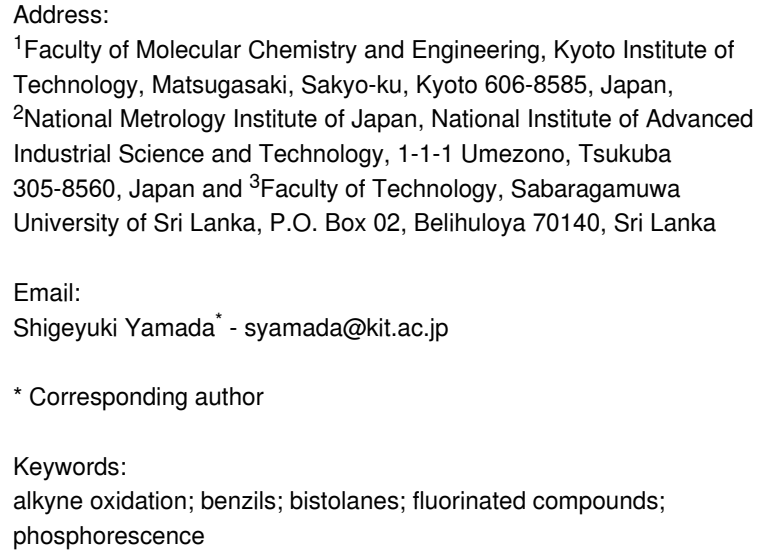

${ }^{1}$ Faculty of Molecular Chemistry and Engineering, Kyoto Institute of Technology, Matsugasaki, Sakyo-ku, Kyoto 606-8585, Japan,

${ }^{2}$ National Metrology Institute of Japan, National Institute of Advanced Industrial Science and Technology, 1-1-1 Umezono, Tsukuba 305-8560, Japan and ${ }^{3}$ Faculty of Technology, Sabaragamuwa University of Sri Lanka, P.O. Box 02, Belihuloya 70140, Sri Lanka

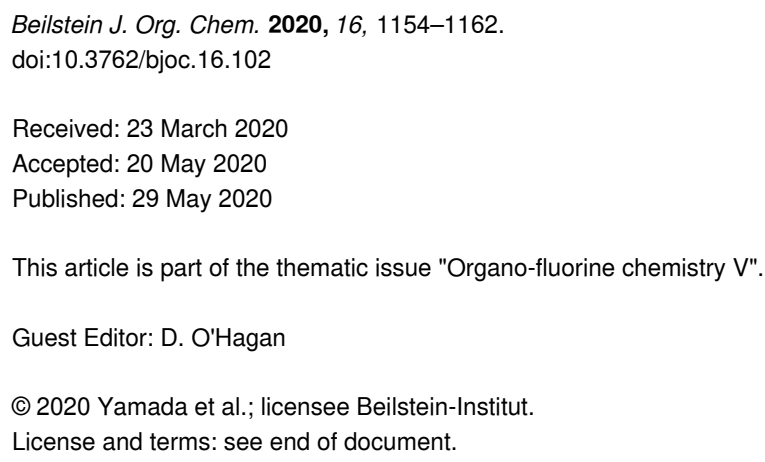

\begin{abstract}
Pure organic phosphorescent molecules are attractive alternatives to transition-metal-complex-based phosphores for biomedical and technological applications owing to their abundance and nontoxicity. This article discloses the design, synthesis, and photophysical properties of fluorinated benzil and bisbenzil derivatives as potential pure organic room-temperature phosphorescent molecules. These compounds were separately converted from the corresponding fluorinated bistolanes via $\mathrm{PdCl}_{2}$-catalyzed oxidation by dimethyl sulfoxide, while nonfluorinated bistolane provided the corresponding bisbenzil derivatives exclusively in a similar manner. Intensive investigations of the photophysical properties of the benzil and bisbenzil derivatives in toluene at $25{ }^{\circ} \mathrm{C}$ showed both fluorescence with a photoluminescence (PL) band at a maximum wavelength $\left(\lambda_{\mathrm{PL}}\right)$ of around $400 \mathrm{~nm}$ and phosphorescence with a PL band at a $\lambda_{\mathrm{PL}}$ of around $560 \mathrm{~nm}$. Interestingly, intersystem crossing effectively caused fluorinated benzils to emit phosphorescence, which may arise from immediate spin-orbit coupling involving the ${ }^{1}(n, \pi) \rightarrow^{3}(\pi, \pi)$ transition, unlike the case of fluorinated or nonfluorinated bisbenzil analogues. These findings offer a useful guide for developing novel pure organic room-temperature phosphorescent materials.
\end{abstract}

\section{Introduction}

The development of organic light-emitting molecules is recognized as one of the most important studies because of the broad application of these compounds as fluorescence probes, bio- imaging materials, and biosensors in biomedical diagnostics [1-4] and as organic light-emitting diodes in the technological field [5-8]. Among the organic light-emitting molecules de- 
veloped thus far, extended $\pi$-conjugated compounds (e.g., pyrenes and perylenes) emit fluorescence, which is a radiative deactivation process from the lowest singlet $\left(S_{1}\right)$ excited state to the ground $\left(\mathrm{S}_{0}\right)$ state [9]. Interestingly, for such $\pi$-conjugated molecules, suitable structural modifications can switch the radiative $S_{1} \rightarrow S_{0}$ process to another radiative deactivation process from the triplet $\left(T_{1}\right)$ excited state to $S_{0}$ via an $S_{1} \rightarrow T_{1}$ intersystem crossing (ISC), resulting in the emission of phosphorescence [9].

Phosphorescent molecules generate two excitons (i.e., $25 \% \mathrm{~S}_{1}$ excitons and $75 \% \mathrm{~T}_{1}$ excitons) by application of an electric field, which is well known for organic light-emitting diodes. $\mathrm{S}_{1}$ excitons are converted to $\mathrm{T}_{1}$ excitons via an ISC process, finally achieving an excellent light-emitting efficiency (up to 100\%) [10]. Therefore, extensive investigations to develop phosphorescent molecules have been performed thus far [11-13]
It has been established that transition metal complexes containing a heavy atom can promote ISC (e.g., Ru [14], Ir [15,16], Pt [17], and $\mathrm{Au}$ [18-21]) (Figure 1A), and this offers a molecular design approach for phosphorescence emission. However, it is becoming necessary to explore alternatives to rare metals because of the latter's scarcity and toxicity. Owing to recent considerable efforts, several molecular designs have been proposed as alternatives, particularly the use of pure organic phosphorescent molecules [22].

For example, methyl 4-bromobenzoate (Figure 1B) exhibits phosphorescence in the crystalline state via nonradiative ISC to the $\mathrm{T}_{1}$ state owing to crystallization-induced restriction of intramolecular motions [23]. Moreover, crystalline 2,5-dihexyloxy4-bromobenzaldehyde displays green phosphorescence, which stems from rapid ISC due to the heavy atom effect via halogen bonding $(\mathrm{C}=\mathrm{O} \cdots \mathrm{Br})[24]$. Moreover, benzophenone- or benzil-
(A)

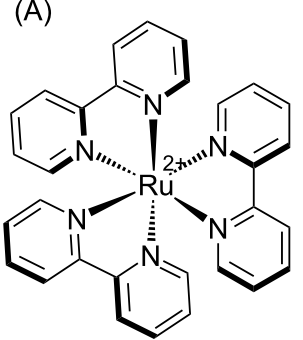
$\left[\mathrm{Ru}(\mathrm{bpy})_{3}\right]^{2+}$<smiles></smiles>

(B)<smiles>COC(=O)c1ccc(Br)cc1</smiles><smiles>[X]c1ccc(C(=O)c2ccc([X])cc2)cc1</smiles>

$\mathrm{X}=\mathrm{H}, \mathrm{F}, \mathrm{Cl}, \mathrm{Br}$

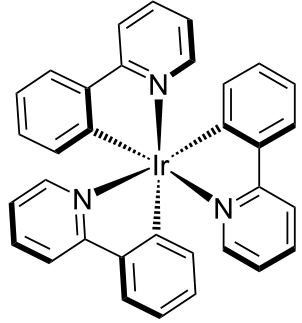

fac-Ir(ppy $)_{3}$

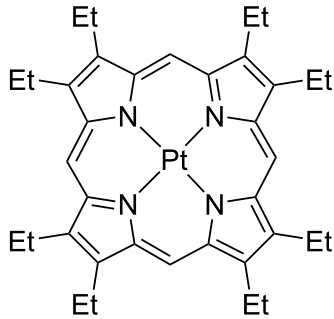

PtOEP
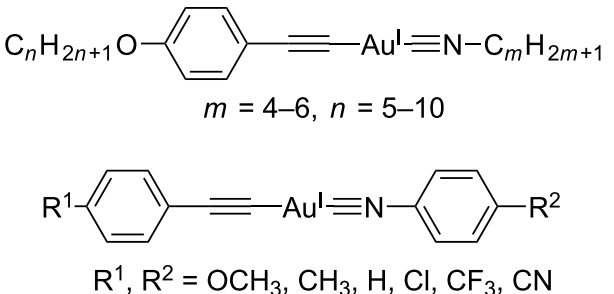
type molecules can achieve long-lived phosphorescence owing to a significant acceleration of spin-orbit coupling based on the El-Sayed rule involving the ${ }^{1}(\mathrm{n}, \pi) \rightarrow^{3}(\pi, \pi)$ transition $[25,26]$.

Over the past few years, our group has intensively investigated fluorinated 1,4-bis(2-phenylethyn-1-yl)benzenes (1), a structural class known as bistolanes (Figure 2A), which show prominent fluorescence not only in dilute solution, but also in the crystalline state [27-31].

As a powerful tool to develop novel pure organic phosphorescent molecules, we envisioned the structural modification of the carbon-carbon triple $(\mathrm{C} \equiv \mathrm{C})$ bond in fluorinated bistolane $\mathbf{1}$ via oxidation to form the corresponding benzil 2 and/or bisbenzil 3 derivatives (Figure 2B). A literature review reveals that bisbenzil-type analogues have not received much attention, despite several publications on benzil-type phosphorescent molecules $[25,26,32]$. In this study, therefore, we examined the synthesis of novel benzil- and bisbenzil-type molecules via oxidation of fluorinated and nonfluorinated bistolane derivatives and evaluated their photophysical properties in detail.

\section{Results and Discussion Synthesis}

This study was initiated with the synthesis of fluorinated bisbenzil derivatives. The $\mathrm{PdCl}_{2}$-catalyzed oxidation of the $\mathrm{C} \equiv \mathrm{C}$ bonds in $\mathbf{1}$ by dimethyl sulfoxide (DMSO) was performed according to a previously reported procedure (Scheme 1) $[33,34]$.
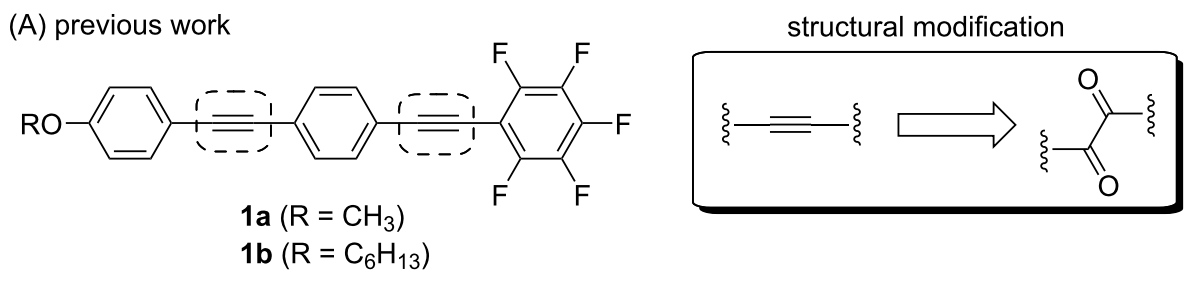

(B) this work

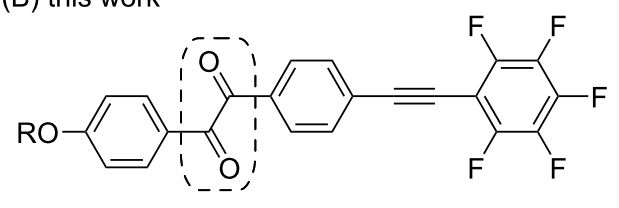

$2 \mathrm{a}\left(\mathrm{R}=\mathrm{CH}_{3}\right)$

2b $\left(\mathrm{R}=\mathrm{C}_{6} \mathrm{H}_{13}\right)$

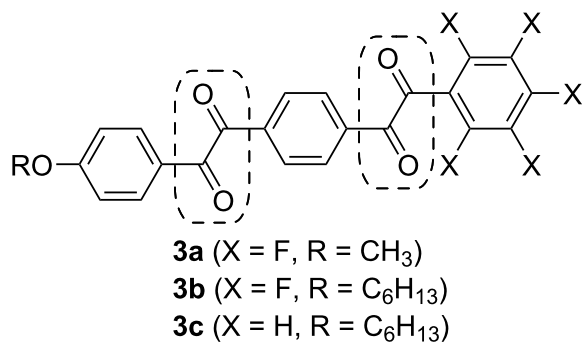

Figure 2: (A) Chemical structures of fluorescent bistolane derivatives previously developed by our group and (B) phosphorescent molecular structures intended for this work.
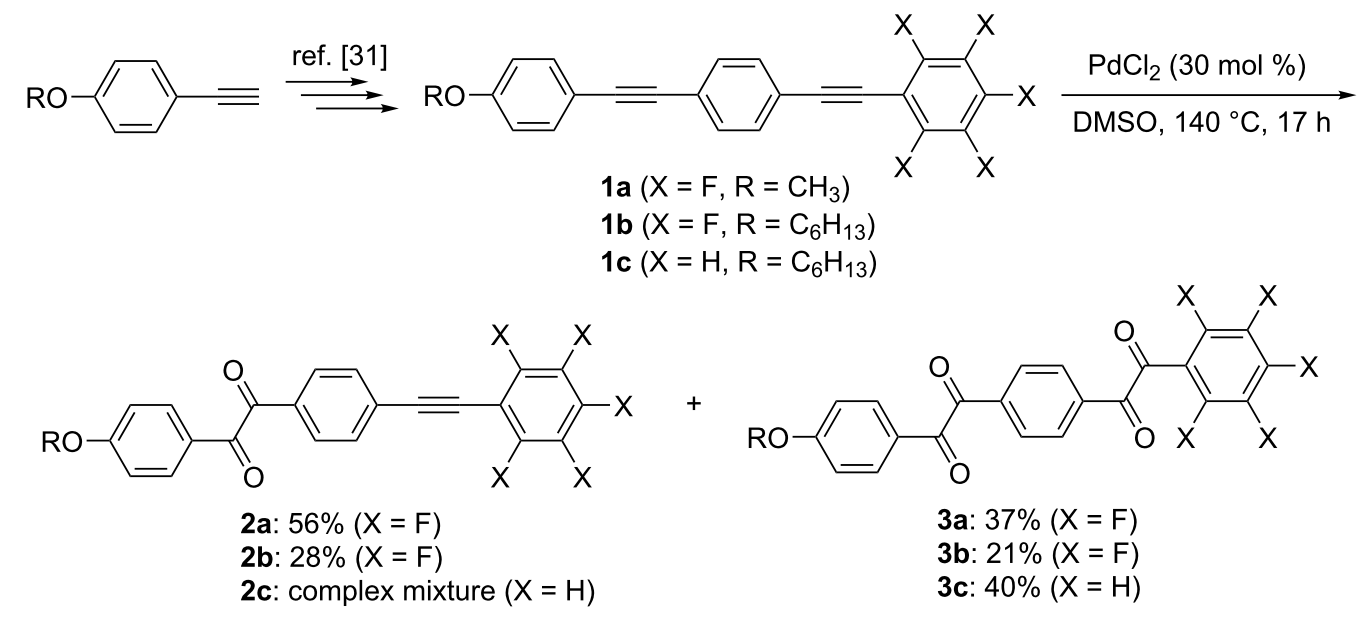
The methoxy-substituted fluorinated bistolane 1a was prepared from commercially available 4-ethynylanisole in four facile steps. Interestingly, stirring 1a in DMSO solution in the presence of $30 \mathrm{~mol} \%$ of $\mathrm{PdCl}_{2}$ at $140{ }^{\circ} \mathrm{C}$ for $17 \mathrm{~h}$ produced two products $(56 \%$ yield for the more polar product and $37 \%$ yield for the less polar product) after purification with column chromatography. Spectroscopic analyses (i.e., ${ }^{1} \mathrm{H},{ }^{19} \mathrm{~F}$, and ${ }^{13} \mathrm{C}$ nuclear magnetic resonance (NMR) spectroscopy, infrared spectroscopy, and high-resolution mass spectrometry) successfully identified the more polar product as the half-oxidized benzil 2a and the less polar one as the fully oxidized bisbenzil 3a. Fluorinated bistolane $\mathbf{1 b}$, bearing a hexyloxy chain, also underwent $\mathrm{PdCl}_{2}$-catalyzed $\mathrm{C} \equiv \mathrm{C}$ oxidation to give rise to the corresponding benzil $\mathbf{2 b}$ and bisbenzil $\mathbf{3 b}$ in $28 \%$ and $21 \%$ yield, respectively. When nonfluorinated bistolane $1 \mathbf{c}$ was used as the substrate, the corresponding bisbenzil $\mathbf{3 c}$ was obtained in $40 \%$ yield as the major product together with an inseparable mixture.

The proposed mechanism of $\mathrm{Pd}(\mathrm{II})$-catalyzed $\mathrm{C} \equiv \mathrm{C}$ oxidation is illustrated in Scheme 2 [33]: The catalytic cycle starts with the coordination of the electron-rich $\mathrm{C} \equiv \mathrm{C}$ bond to the electron-deficient divalent $\mathrm{Pd}$ center, forming the corresponding $\pi$-complex (Int-A). Int-A smoothly undergoes nucleophilic attack by the oxygen atom in DMSO to construct a cationic vinyl-palladium(II) species (Int-B). Further nucleophilic attack of another DMSO molecule against Int-B, followed by elimination of dimethyl sulfide, furnishes a cationic intermediate (Int-C).
Finally, immediate elimination of dimethyl sulfide and the $\mathrm{Pd}$ (II) catalyst gives rise to the corresponding benzil $\mathbf{2}$, after which the eliminated $\mathrm{Pd}(\mathrm{II})$ catalyst is recycled to provide the oxidation products. The fully oxidized bisbenzil $\mathbf{3}$ is generated after further $\mathrm{Pd}(\mathrm{II})$-catalyzed $\mathrm{C} \equiv \mathrm{C}$ oxidation of the halfoxidized benzil 2 via the same catalytic cycle.

Considering the proposed reaction mechanism, the successful isolation of the half-oxidized benzil derivatives $\mathbf{2 a}$ and $\mathbf{2} \mathbf{b}$ from the oxidation of fluorinated bistolanes $\mathbf{1 a}$ and $\mathbf{1 b}$, respectively, may be due to the decreased reactivity of the $\mathrm{C} \equiv \mathrm{C}$ bond toward $\mathrm{Pd}(\mathrm{II})$-catalyzed $\mathrm{C} \equiv \mathrm{C}$ oxidation caused by the adjacent electrondeficient fluorinated aromatic ring. To confirm the electronwithdrawing effect of this fluorinated aromatic ring, the electronic charge at the adjacent $\mathrm{C} \equiv \mathrm{C}$ bond was calculated by density functional theory (DFT) using the Gaussian 16 (Revision B.01) software package [35]. As typical examples, the molecular geometries of 1a and 1c were optimized at the CAMB3LYP/6-31+G(d) level of theory. The absence of any imaginary frequency in the vibrational analysis proved that the calculated structures are the minima. Figure 3 shows the calculated Mulliken charge distributions of fluorinated 1a and nonfluorinated 1c.

The sp-hybridized carbon adjacent to the fluorinated aromatic ring of 1a has a significant positive Mulliken charge (+0.472), while that adjacent to the nonfluorinated aromatic ring of $1 \mathrm{c}$ has a negative charge $(-0.304)$. This clearly indicates that the fluo-

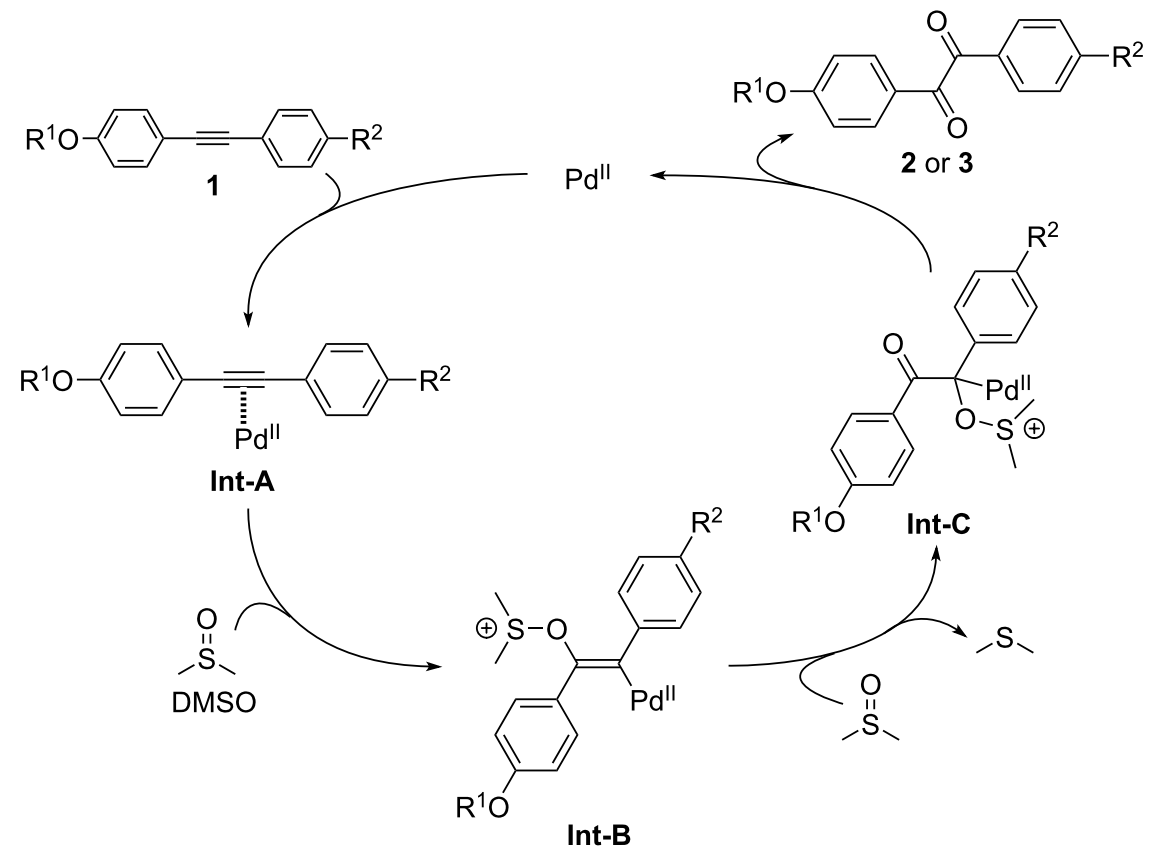

Scheme 2: Proposed mechanism of Pd(II)-catalyzed alkyne oxidation by dimethyl sulfoxide (DMSO). 


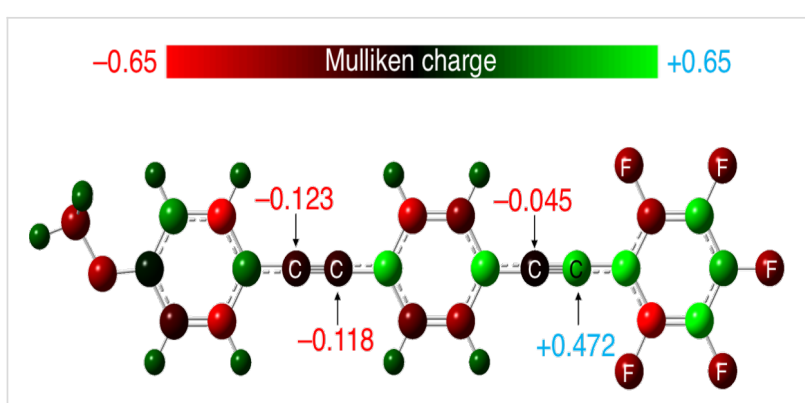

Fluorinated 1a

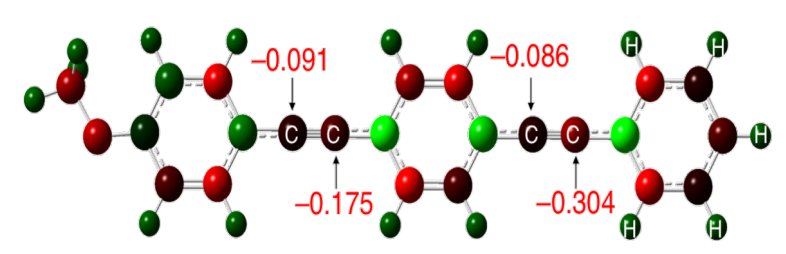

Non-fluorinated 1c

Figure 3: Mulliken charge distributions of fluorinated 1a and nonfluorinated 1c obtained from density functional theory calculations [CAM$B 3 L Y P / 6-31+G(d)$ level].

rinated aromatic ring retards the $\mathrm{Pd}(\mathrm{II})$-catalyzed oxidation of the adjacent $\mathrm{C} \equiv \mathrm{C}$ bond, thereby allowing the isolation of the half-oxidized benzil derivative 2a. On the basis of this theoretical investigation, the unique reactivities of bistolanes with fluo- rinated and nonfluorinated aromatic rings toward oxidation by DMSO can be rationalized.

\section{Photophysical behavior}

Our interest was then directed toward the photophysical properties of benzil and bisbenzil derivatives, which were freshly purified by column chromatography (eluent: hexane/EtOAc $=5: 1$ for benzil and 10:1 for bisbenzil) and subsequently recrystallized from hexane. The sample solution concentrations in toluene were $1.0 \times 10^{-5}$ and $1.0 \times 10^{-3} \mathrm{M}$ for the absorption and photoluminescence (PL) measurements, respectively, and the absorption and PL spectra are shown in Figure 4. The photophysical data obtained from these measurements are summarized in Table 1.

The methoxy-substituted fluorinated benzil 2a in toluene absorbs UV light at 315 and $295 \mathrm{~nm}$ with molar extinction coefficients $(\varepsilon)$ of 36500 and $28700 \mathrm{M}^{-1} \cdot \mathrm{cm}^{-1}$, respectively (Figure 4A). Similarly, the toluene solution of the fluorinated benzil with a hexyloxy chain (2b) absorbs UV light at 314 ( $\varepsilon: 30400 \mathrm{M}^{-1} \cdot \mathrm{cm}^{-1}$ ) and $293 \mathrm{~nm}\left(\varepsilon: 40500 \mathrm{M}^{-1} \cdot \mathrm{cm}^{-1}\right.$ ) (Figure 4B). Both 2a and $\mathbf{2 b}$ exhibit weak absorption at around $400 \mathrm{~nm}\left(\varepsilon: \approx 170 \mathrm{M}^{-1} \cdot \mathrm{cm}^{-1}\right)$. As shown in Figure $4 \mathrm{C}-\mathrm{E}$, on the other hand, the bisbenzil derivatives $\mathbf{3 a}-\mathbf{c}$ show an absorption band at $290 \mathrm{~nm}\left(\varepsilon: 29600-51200 \mathrm{M}^{-1} \cdot \mathrm{cm}^{-1}\right)$ as the major signal, together with a quite weak absorption band at
(A) $2 \mathbf{a}$

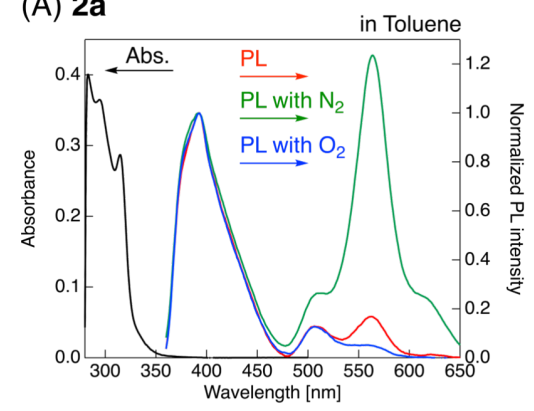

(C) $3 a$

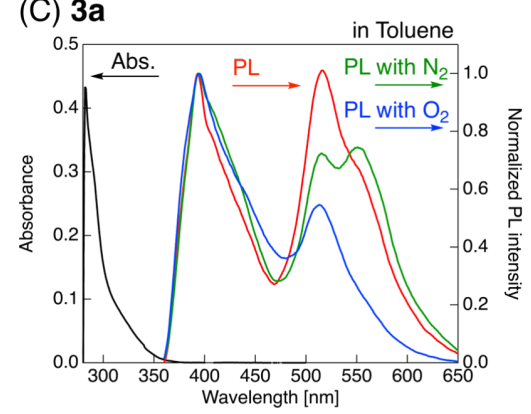

(B) $\mathbf{2 b}$

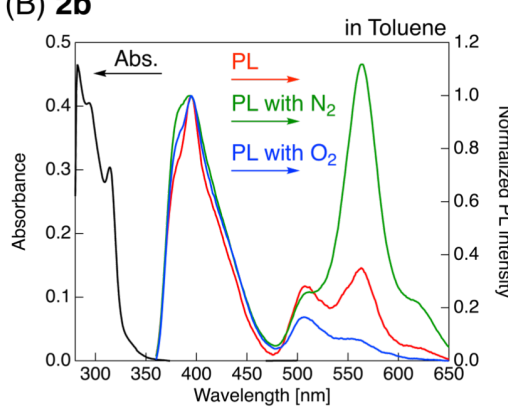

(D) $\mathbf{3 b}$

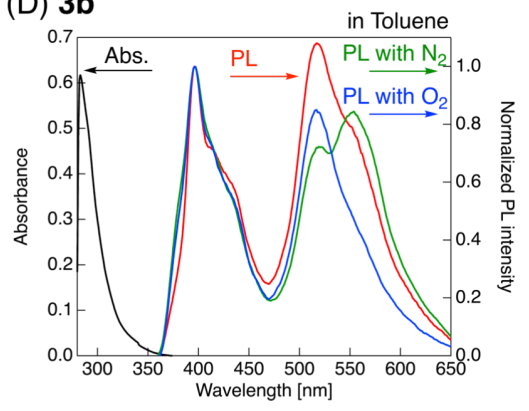

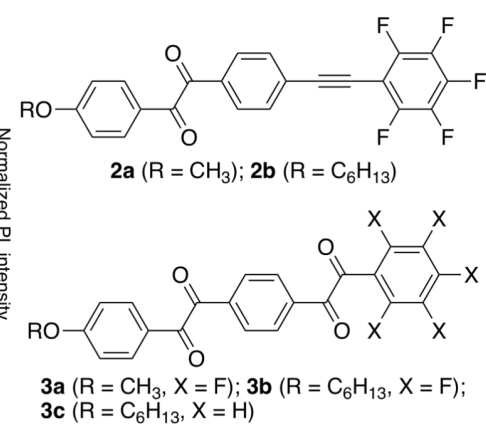

(E) $3 c$

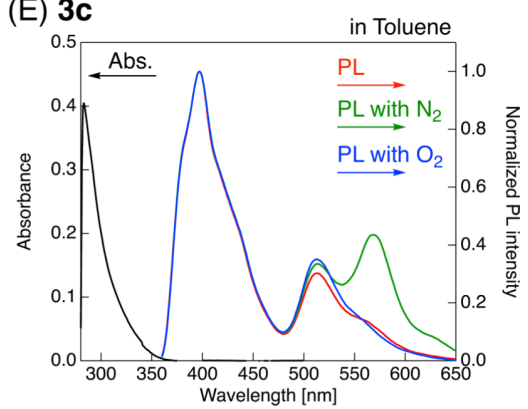

Figure 4: Absorption and photoluminescence $(P L)$ spectra of $(A) \mathbf{2 a},(B) \mathbf{2 b},(C) \mathbf{3 a},(D) \mathbf{3 b}$, and $(E) \mathbf{3 c}$ in toluene solution. Concentrations: $1.0 \times 10^{-5}$ and $1.0 \times 10^{-3} \mathrm{M}$ for absorbance and PL measurements, respectively. Color legend: black: absorption, red: PL as prepared, green: PL under $\mathrm{N}_{2}$ atmosphere, and blue: PL under $\mathrm{O}_{2}$ atmosphere. 
Table 1: Photophysical data from ultraviolet (UV)-visible absorption and steady-state photoluminescence (PL) measurements ${ }^{\mathrm{a}}$.

\begin{tabular}{|c|c|c|c|c|c|}
\hline & \multirow[t]{2}{*}{$\lambda_{\mathrm{abs}}[\mathrm{nm}]\left(\varepsilon\left[\mathrm{M}^{-1} \mathrm{~cm}^{-1}\right]\right)$} & \multirow[t]{2}{*}{$\lambda_{\mathrm{PL}}[\mathrm{nm}]^{\mathrm{b}}\left(\Phi_{\mathrm{PL}}\right)^{\mathrm{c}}$} & \multicolumn{3}{|c|}{$I_{560} / I_{395}$} \\
\hline & & & pristine & $\mathrm{N}_{2}$ & $\mathrm{O}_{2}$ \\
\hline $2 a$ & $\begin{array}{l}295(28700), 315(36500), 407 \\
(160)\end{array}$ & $\begin{array}{l}395,406 \mathrm{sh}^{\mathrm{d}}, 507,563 \\
(0.018)\end{array}$ & 0.17 & 1.24 & 0.05 \\
\hline $2 b$ & $\begin{array}{l}293(40500), 314(30400), 407 \\
(180)\end{array}$ & $\begin{array}{l}395,406 \text { sh, } 507,563 \\
(0.015)\end{array}$ & 0.35 & 1.12 & 0.08 \\
\hline $\mathbf{3 a}$ & $290(30500), 405$ (180) & 393,406 sh, $516,551(<0.01)$ & 0.61 & 0.74 & 0.19 \\
\hline $3 b$ & 290 (51200), 405 (212) & $\begin{array}{l}396,412,517,554 \\
(<0.01)\end{array}$ & 0.79 & 0.84 & 0.50 \\
\hline 3c & 290 (29600), $402(260)$ & $\begin{array}{l}397,412,514,569 \\
(<0.01)\end{array}$ & 0.14 & 0.44 & 0.14 \\
\hline
\end{tabular}

aToluene solution (concentrations: $1.0 \times 10^{-5}$ and $1.0 \times 10^{-3} \mathrm{M}$ for UV-visible absorption and PL measurements, respectively); ${ }^{\mathrm{E}}$ Excitation wavelength: $350 \mathrm{~nm}$; ' Quantum yield measured using a calibrating sphere. Excitation wavelength: $290 \mathrm{~nm}$. dShoulder peak.

402-405 nm ( $\left.\varepsilon: 180-260 \mathrm{M}^{-1} \cdot \mathrm{cm}^{-1}\right)$. To gain more information about the slight difference between the absorption behaviors of the benzil and bisbenzil derivatives, DFT and time-dependent DFT (TD-DFT) calculations at the CAM-B3LYP/6-
$31+\mathrm{G}(\mathrm{d})$ level of theory were performed for fluorinated benzil 2a and bisbenzil derivative 3a as representative examples. Figure 5 shows the distributions of molecular orbitals involved in vertical electronic transitions in $\mathbf{2 a}$ and $\mathbf{3 a}$.
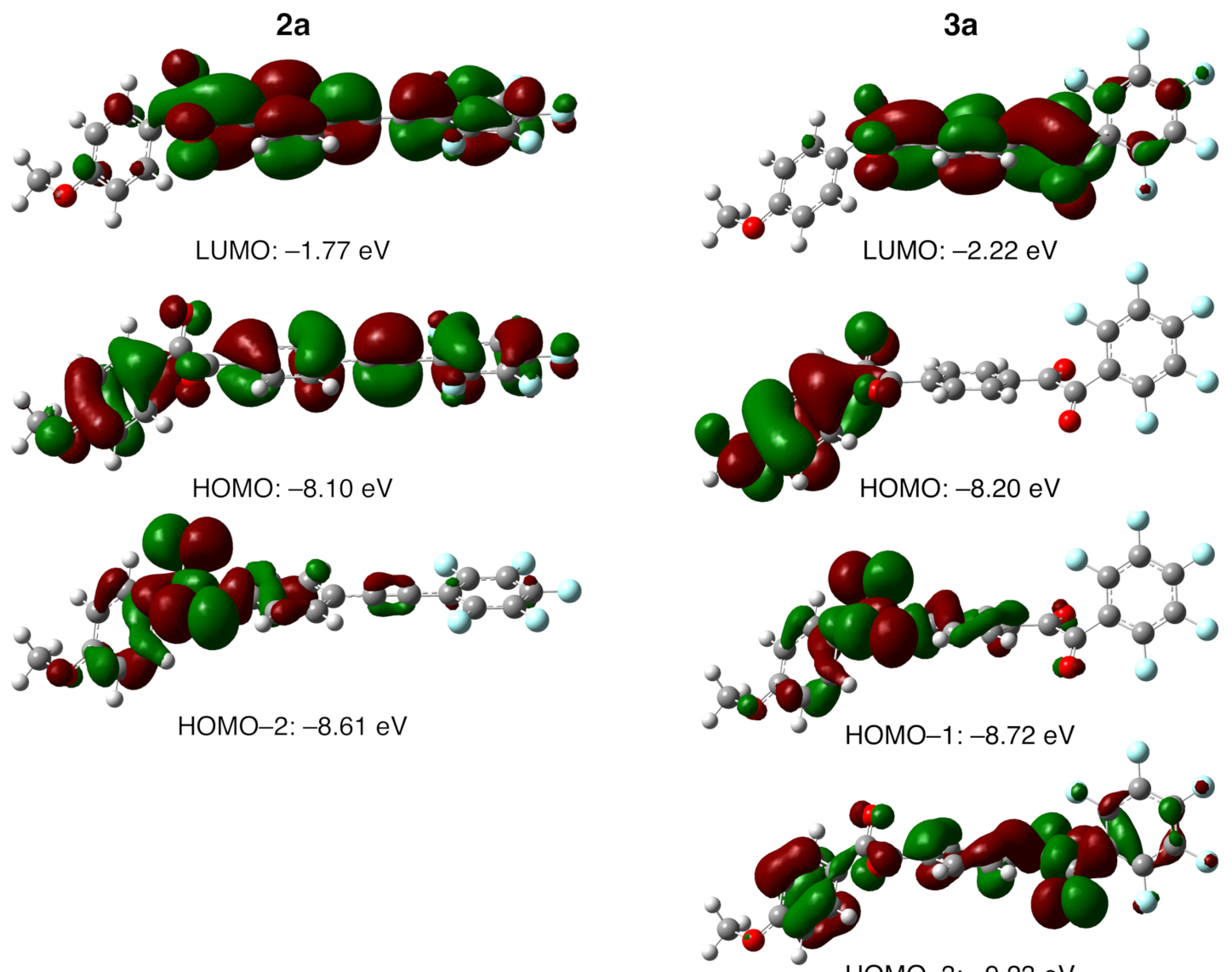

HOMO-3: -9.23 eV

Figure 5: Distributions of molecular orbitals (isosurface value: 0.04 a.u.) involved in vertical electronic transitions in $2 \mathbf{a}$ and $3 \mathbf{3}$ calculated using density functional theory (DFT) and time-dependent DFT at the CAM-B3LYP/6-31+G(d) level (HOMO: highest occupied molecular orbital, LUMO: lowest unoccupied molecular orbital). 
The main electronic transition with a relatively large oscillator strength $(f)$ in both $\mathbf{2 a}$ and $\mathbf{3 a}$ is the highest occupied molecular orbital (HOMO) $\rightarrow$ lowest unoccupied molecular orbital (LUMO) transition. Focusing on the orbital distribution, the HOMO lobe of $\mathbf{2 a}$ covers the entire molecule, while the LUMO lobe is localized at the tolane moiety. In the case of $\mathbf{3 a}$, the HOMO lobe is localized at the methoxy-substituted benzene ring, while the LUMO lobe is localized at the central benzene ring. Accordingly, it can be concluded that the absorption bands at the short-wavelength region (around 290-315 nm) stems from the $\pi-\pi^{*}$ transition. The TD-DFT calculation also reveals that $\mathrm{n}-\pi^{*}$ transitions (e.g., HOMO-2 $\rightarrow$ LUMO for $\mathbf{2 a}$ and HOMO-3 $\rightarrow$ LUMO for 3a) have small values of $f$; thus, the small absorption band at around $400 \mathrm{~nm}$ can be safely attributed to an $\mathrm{n}-\pi^{*}$ transition.

Upon irradiation of the toluene solutions of benzil derivatives 2a and 2b with a $350 \mathrm{~nm}$ UV light, three PL bands at 395, 507, and $563 \mathrm{~nm}$, along with a shoulder signal at around $406 \mathrm{~nm}$, are observed (Figure 4A and 4B). The bisbenzil derivatives, i.e., 3a-c, also show similar PL behavior to the aforementioned benzil analogues: four PL bands with $\lambda_{\mathrm{PL}}$ of 393-397, 406-412, 514-517, and 551-569 nm are observed. To gain more information about the PL process in benzils and bisbenzils, the PL spectra of the toluene solutions $\left(1.0 \times 10^{-3} \mathrm{M}\right)$ were acquired after bubbling with $\mathrm{N}_{2}$ or $\mathrm{O}_{2}$ gas for $30 \mathrm{~min}$. In general, an $\mathrm{O}_{2}$-saturated environment strongly deactivates the triplet states; thus, PL emission stems only from fluorescence. On the other hand, elimination of $\mathrm{O}_{2}$ gas from a solution by bubbling with an inert gas $\left(\mathrm{N}_{2}\right.$ or Ar) allows the triplet states to survive for a long lifetime, which possibly leads to a phosphorescence emission. Hence, the elimination of $\mathrm{O}_{2}$ gas from solutions by $\mathrm{N}_{2}$ gas bubbling (or addition of $\mathrm{O}_{2}$ gas in solutions) can judge the presence of phosphorescence, as well as the assignment of PL bands. The obtained PL spectra are superimposed on the PL spectra of a pristine sample (Figure 4). Upon bubbling the solution with $\mathrm{N}_{2}$ gas for 30 min, a dramatic enhancement of the PL intensities of benzils $2 \mathbf{a}$ and $\mathbf{2 b}$ at $\lambda_{\mathrm{PL}}=563 \mathrm{~nm}$ is observed. The PL intensities of bisbenzils 3a-c at the long-wavelength region between 551 and $569 \mathrm{~nm}$ also increase, although the increment rates are not as high as those of $\mathbf{2 a}$ and $\mathbf{2} \mathbf{b}$. On the contrary, bubbling the toluene solutions of benzil or bisbenzil derivatives with $\mathrm{O}_{2}$ gas causes the intensity of the long-wavelength PL band to decrease compared with that of the pristine solution, while the other remaining PL bands in the short-wavelength region do not change. Judging from the PL behavior under $\mathrm{N}_{2}$ or $\mathrm{O}_{2}$ flow conditions, the PL bands at the shortwavelength region around $395 \mathrm{~nm}$ and long-wavelength region around $560 \mathrm{~nm}$ can be safely considered fluorescence via radiative deactivation from the $S_{1}$ excited state to the $S_{0}$ state and phosphorescence via electronic transition from the $\mathrm{T}_{1}$ excited state to the $\mathrm{S}_{0}$ state, respectively. Accordingly, fluorinated benzils and bisbenzils show room-temperature phosphorescence in the solution state.

To understand the effects of structural modification (i.e., the benzil structure with a tolane vs bisbenzil moiety) and incorporation of fluorine atoms on the phosphorescence, the ratio between the peak intensities at $\approx 395$ and $\approx 560 \mathrm{~nm}\left(I_{560} / I_{395}\right)$ was quantitatively calculated, and the results are summarized in Table 1 . The $I_{560} / I_{395}$ values of benzils $2 \mathbf{a}$ and $2 \mathbf{b}$ under $\mathrm{N}_{2}$ flow conditions increase up to sevenfold compared with those of the corresponding pristine solutions. On the other hand, the increase in the $I_{560} / I_{395}$ values of fluorinated bisbenzil derivatives $3 \mathbf{a}$ and $\mathbf{3 b}$ is low (only 1.1 times) under $\mathrm{N}_{2}$ flow conditions, although the PL intensity of nonfluorinated $\mathbf{3 c}$ increases by approximately three times. Judging from these comprehensive observations, the benzil structure promotes ISC from $S_{1}$ to $\mathrm{T}_{1}$, causing increment phosphorescence, unlike the corresponding bisbenzil scaffold. Moreover, fluorine substituents on the bisbenzil molecules cause significant retardation of ISC, leading to a weaker phosphorescence intensity.

Additionally, the quantum yields $\left(\Phi_{\mathrm{PL}}\right)$ of the PL bands in the range of 350-600 $\mathrm{nm}$ were acquired using an absolute quantum yield measurement system with a calibrated integrating sphere. All samples have a low $\Phi_{\mathrm{PL}}$ of less than 0.02 (Table 1), meaning that most of the excited states of all samples deactivate nonradiatively. At the moment, we cannot certify the origin of the low $\Phi_{\mathrm{PL}}$ in terms of the molecular properties, for instance, the main pathway of nonradiative deactivation. Experiments are currently being conducted to better understand the photophysical mechanisms of the excited-state dynamics of these benzil and bisbenzil derivatives.

\section{Conclusion}

In this article, we described the design and synthesis of benzilor bisbenzil-based room-temperature phosphorescent molecules via a simple oxidation protocol for fluorescent bistolane derivatives. Nonfluorinated bistolane derivatives exclusively gave the corresponding products with a bisbenzil scaffold, whereas the fluorinated bistolane derivatives generated not only mono-oxidized benzil derivatives bearing a fluorinated tolane scaffold, but also the corresponding bis-oxidized bisbenzil derivatives. Based on theoretical calculations, the selective formation of the fluorinated analogues stemmed from the slight modulation of the charge distribution at the alkyne moiety of the reactant induced by the electron-withdrawing fluorine atoms. Evaluation of the photophysical behavior of the benzils and bisbenzils through several PL measurements under $\mathrm{N}_{2}$ and $\mathrm{O}_{2}$ flow conditions probed the successful room-temperature phosphorescence of the compounds in toluene solution. A fuller 
understanding of the excited-state dynamics of these benzil and bisbenzil derivatives will assist the development of environmentally benign, pure organic phosphorescent materials.

\section{Supporting Information}

Experimental procedures for the synthesis and characterization of fluorinated benzils $\mathbf{2 a}$ and $\mathbf{2 b}$, fluorinated bisbenzils $\mathbf{3 a}$ and $\mathbf{3 b}$, and nonfluorinated bisbenzil 3c. ${ }^{1} \mathrm{H},{ }^{13} \mathrm{C}$, and ${ }^{19} \mathrm{~F}$ NMR spectra of $\mathbf{2 a}, \mathbf{2} \mathbf{b}$, and 3a-c. Cartesian coordinates of the optimized geometries of 1a, 1c, 2a, and 3a obtained from DFT calculations.

\section{Supporting Information File 1}

Experimental preocedures, NMR spectra and Cartesian coordinates.

[https://www.beilstein-journals.org/bjoc/content/ supplementary/1860-5397-16-102-S1.pdf]

\section{Funding}

The following sources of funding are acknowledged: Japan Society for the Promotion of Science (JSPS) KAKENHI Grantin-Aid for Scientific Research (C) (Grant No. JP18K05262) and the AIST Nanocharacterization Facility (ANCF) platform as part of a program of the "Nanotechnology Platform" of the Ministry of Education, Culture, Sports, Science and Technology (MEXT), Japan.

\section{ORCID ${ }^{\circledR}$ iDs}

Shigeyuki Yamada - https://orcid.org/0000-0002-6379-0447

Takuya Hosokai - https://orcid.org/0000-0001-9164-4159

Kaveenga Rasika Koswattage - https://orcid.org/0000-0001-7183-406X

\section{Preprint}

A non-peer-reviewed version of this article has been previously published as a preprint doi:10.3762/bxiv.2020.31.v1

\section{References}

1. Singh, H.; Tiwari, K.; Tiwari, R.; Pramanik, S. K.; Das, A. Chem. Rev. 2019, 119, 11718-11760. doi:10.1021/acs.chemrev.9b00379

2. Mei, J.; Huang, Y.; Tian, H. ACS Appl. Mater. Interfaces 2018, 10, 12217-12261. doi:10.1021/acsami.7b14343

3. Chen, X.; Wang, F.; Hyun, J. Y.; Wei, T.; Qiang, J.; Ren, X.; Shin, I.; Yoon, J. Chem. Soc. Rev. 2016, 45, 2976-3016. doi:10.1039/c6cs00192k

4. Ma, Y.; Zhang, Y.; Yu, W. W. J. Mater. Chem. C 2019, 7, 13662-13679. doi:10.1039/c9tc04065j

5. Yersin, H., Ed. Highly Efficient OLEDs: Materials Based on Thermally Activated Delayed Fluorescence; Wiley-VCH: Weinheim, Germany, 2018. doi:10.1002/9783527691722
6. Gaspar, D. J.; Polikarpov, E., Eds. OLED Fundamentals: Materials Devices, and Processing of Organic Light-Emitting Diodes; CRC Press: Boca Raton, FL, USA, 2015. doi:10.1201/b18485

7. Su, L.; Fan, X.; Yin, T.; Wang, H.; Li, Y.; Liu, F.; Li, J.; Zhang, H.; Xie, H. Adv. Opt. Mater. 2020, 8, 1900978. doi:10.1002/adom.201900978

8. Ostroverkhova, O. Chem. Rev. 2016, 116, 13279-13412. doi:10.1021/acs.chemrev.6b00127

9. Ronda, C. R. Emission and Excitation Mechanisms of Phosphors. In Luminescence: From Theory to Applications; Ronda, C. R., Ed.; Wiley-VCH: Weinheim, Germany, 2007; pp 1-34. doi:10.1002/9783527621064.ch1

10. Yersin, H.; Rausch, A. F.; Czerwieniec, R. Organometallic Emitters for OLEDs: Triplet Harvesting, Singlet Harvesting, Case Structures, and Trends. In Physics of Organic Semiconductors; Brütting, W.; Adachi, C., Eds.; Wiley-VCH: Weinheim, Germany, 2012; pp 371-424. doi:10.1002/9783527654949.ch13

11. Wang, W.; Zhang, Y.; Jin, W. J. Coord. Chem. Rev. 2020, 404, 213107. doi:10.1016/j.ccr.2019.213107

12. Zhan, G.; Liu, Z.; Bian, Z.; Huang, C. Front. Chem. (Lausanne, Switz.) 2019, 7, 305. doi:10.3389/fchem.2019.00305

13. Qu, G.; Zhang, Y.; Ma, X. Chin. Chem. Lett. 2019, 30, 1809-1814. doi:10.1016/j.cclet.2019.07.042

14. Crosby, G. A. Acc. Chem. Res. 1975, 8, 231-238. doi:10.1021/ar50091a003

15. Baldo, M. A.; Lamansky, S.; Burrows, P. E.; Thompson, M. E.; Forrest, S. R. Appl. Phys. Lett. 1999, 75, 4-6. doi:10.1063/1.124258 16. Adachi, C.; Baldo, M. A.; Forrest, S. R.; Thompson, M. E. Appl. Phys. Lett. 2000, 77, 904-906. doi:10.1063/1.1306639

17. Baldo, M. A.; O'Brien, D. F.; You, Y.; Shoustikov, A.; Sibley, S.; Thompson, M. E.; Forrest, S. R. Nature 1998, 395, 151-154. doi:10.1038/25954

18. Yam, V. W.-W.; Wong, K. M.-C.; Hung, L.-L.; Zhu, N. Angew. Chem., Int. Ed. 2005, 44, 3107-3110. doi:10.1002/anie.200500253

19. Yamada, S.; Yamaguchi, S.; Tsutsumi, O. J. Mater. Chem. C 2017, 5, 7977-7984. doi:10.1039/c7tc00728k

20. Fujisawa, K.; Kawakami, N.; Onishi, Y.; Izumi, Y.; Tamai, S.; Sugimoto, N.; Tsutsumi, O. J. Mater. Chem. C 2013, 1, 5359-5366. doi:10.1039/c3tc31105h

21. Seki, T.; Takamatsu, Y.; Ito, H. J. Am. Chem. Soc. 2016, 138, 6252-6260. doi:10.1021/jacs.6b02409

22. Kenry; Chen, C.; Liu, B. Nat. Commun. 2019, 10, 2111. doi:10.1038/s41467-019-10033-2

23. Yuan, W. Z.; Shen, X. Y.; Zhao, H.; Lam, J. W. Y.; Tang, L.; Lu, P.; Wang, C.; Liu, Y.; Wang, Z.; Zheng, Q.; Sun, J. Z.; Ma, Y.; Tang, B. Z. J. Phys. Chem. C 2010, 114, 6090-6099. doi:10.1021/jp909388y

24. Bolton, O.; Lee, K.; Kim, H.-J.; Lin, K. Y.; Kim, J. Nat. Chem. 2011, 3, 205-210. doi:10.1038/nchem.984

25. Zhao, W.; He, Z.; Lam, J. W. Y.; Peng, Q.; Ma, H.; Shuai, Z.; Bai, G.; Hao, J.; Tang, B. Z. Chem 2016, 1, 592-602. doi:10.1016/j.chempr.2016.08.010

26. Lower, S. K.; El-Sayed, M. A. Chem. Rev. 1966, 66, 199-241. doi:10.1021/cr60240a004

27. Morita, M.; Yamada, S.; Agou, T.; Kubota, T.; Konno, T. Appl. Sci. 2019, 9, 1905. doi:10.3390/app9091905

28. Yamada, S.; Miyano, K.; Agou, T.; Kubota, T.; Konno, T. Crystals 2019, 9, 195. doi:10.3390/cryst9040195

29. Yamada, S.; Tanaka, T.; Ichikawa, T.; Konno, T. ACS Omega 2019, 4, 3922-3932. doi:10.1021/acsomega.8b03543 
30. Yamada, S.; Morita, M.; Agou, T.; Kubota, T.; Ichikawa, T.; Konno, T. Org. Biomol. Chem. 2018, 16, 5609-5617. doi:10.1039/c8ob01497c

31. Yamada, S.; Miyano, K.; Konno, T.; Agou, T.; Kubota, T.; Hosokai, T. Org. Biomol. Chem. 2017, 15, 5949-5958. doi:10.1039/c7ob01369h

32. Gong, Y. Y.; Tan, Y. Q.; Li, H.; Zhang, Y. R.; Yuan, W. Z.;

Zhang, Y. M.; Sun, J. Z.; Tang, B. Z. Sci. China: Chem. 2013, 56,

1183-1186. doi:10.1007/s11426-013-4930-9

33. Muzart, J. J. Mol. Catal. A: Chem. 2011, 338, 7-17.

doi:10.1016/j.molcata.2011.01.030

34. Chi, K.-W.; Yusubov, M. S.; Filimonov, V. D. Synth. Commun. 1994, 24, 2119-2122. doi:10.1080/00397919408010224

35. Gaussian 16, Revision B.01; Gaussian, Inc.: Wallingford, CT, USA, 2016.

\section{License and Terms}

This is an Open Access article under the terms of the Creative Commons Attribution License

(http://creativecommons.org/licenses/by/4.0). Please note that the reuse, redistribution and reproduction in particular requires that the authors and source are credited.

The license is subject to the Beilstein Journal of Organic Chemistry terms and conditions:

(https://www.beilstein-journals.org/bjoc)

The definitive version of this article is the electronic one which can be found at: doi:10.3762/bjoc. 16.102 